\title{
Publisher Correction: High-energy long-cycling all-solid-state lithium metal batteries enabled by silver-carbon composite anodes
}

Yong-Gun Lee (1D, Satoshi Fujiki (iD, Changhoon Jung, Naoki Suzuki, Nobuyoshi Yashiro, Ryo Omoda, Dong-Su Ko, Tomoyuki Shiratsuchi, Toshinori Sugimoto, Saebom Ryu D, Jun Hwan Ku, Taku Watanabe @ , Youngsin Park, Yuichi Aihara (D), Dongmin Im (1) and In Taek Han

Correction to: Nature Energy https://doi.org/10.1038/s41560-020-0575-Z, published online 9 March 2020.

In the version of this Article originally published, in the sentence beginning "Furthermore, the Li transference number..., " $\left.t_{\mathrm{Li}^{+}} \approx 0.5\right)$ " was incorrectly written as " $\left(t_{\mathrm{Li}^{+}} t_{\mathrm{Li}+} \approx 0.5\right)$ ". In addition, the labels in Fig. 1a were missing. These errors have now been corrected.

Published online: 20 March 2020

https://doi.org/10.1038/s41560-020-0604-y

(๑) The Author(s), under exclusive licence to Springer Nature Limited 2020 